\title{
Limited Surgery in Early Gastric Cancer
}

\author{
S. Gretschel P. M. Schlag \\ Klinik für Chirurgie und Chirurgische Onkologie, Universitätsmedizin Charité, Campus Berlin Buch, Berlin, Germany
}

With a 5-year survival rate of more than $90 \%$, early stage gastric carcinoma has a far better prognosis than the more advanced stages. However, this survival advantage is currently achieved at the cost of subtotal or total gastrectomy. It is, thus, understandable that physicians are searching for ways to reach the same result by limited approaches. With this goal in mind, several endoscopic and laparoscopic procedures have been developed. For example, endoscopic mucosa resection is increasingly employed, especially in early cancers of limited extension [1]. Also, total or partial gastrectomies with limited lymphadenectomy (D0 or D1) are performed by minimal access surgery $[2,3]$. Profound experience with these methods is a prerogative for their successful application. However, the indication for limited surgery depends on tumor localization and lymphatic involvement, too. The article by Skoropad et al. [4] in this issue of ONKOLOGIE confirms the well-known fact that nodal involvement impairs the prognosis of early gastric cancer, even after radical surgery. As a consequence, a limited approach is especially questionable in the presence of nodal metastases. The probability of lymphatic involvement in early gastric carcinoma is approximately $10-12 \%$. It is lower (4\%) in mucosal carcinomas and much higher (up to $23 \%$ ) in submucosal tumors. Metastases are not confined to the D1 compartment but can also be found in the D2 compartment [5]. Therefore, an exact lymphatic staging is a prerequisite for limited surgery in early gastric cancer. Three possible approaches exist:

1. Prediction of lymphatic state on the basis of the characteristics of the primary tumor. These comprise size, appearance (elevated, depressed, ulcerated etc.), histological differentiation (Lauren classification), and depth of invasion (mucosa/submucosa). Currently, molecular markers (e.g. VEGF) in biopsy specimens are tested as predictors for nodal involvement. However, results are still contradictory. Gene chip analyses of tumor tissues will eventually give more conclusive data in the future.
2. Direct differentiation of involved and uninvolved lymph nodes with imaging procedures such as MRT/MRS, PET, or endosonographically guided fine-needle biopsy. However, these procedures have a sensitivity below 70-80\% and are therefore at the moment of limited value in the decision pro or contra limited surgery.

3. Much more promising is the method of sentinel lymph node biopsy (SLNB). This approach has, also according to our own experience, an acceptably high sensitivity and specificity [6-10]. New flexible nuclide detector probes or fluorescent dyes allow us to expect further advancements. Another advantage of SLNB lies in the subtile histopathologic characterization of the sentinel nodes. This increases the detection of micrometastases or single tumor cells, which, in the lymph nodes, according to recent investigations, are a relevant and important prognostic factor [11, 12]. Upstaging rates of otherwise node negative patients are as high as $40 \%$ with this method [10, 13]. However, the feasibility and accuracy of this technique under laparoscopic conditions has to be tested $[14,15]$. SLNB could be a further step on the way to stage-adapted limited surgical therapy of early gastric carcinoma.

Thus, the conclusions of Skoropad and colleagues that therapy in early gastric cancer should be limited in most patients is not as yet applicable in reality. The key to the application of limited surgical procedures, such as laparoscopic or endoscopic surgical procedures, is the exact identification of nodal involvement. A reliable diagnostic procedure for this is still missing. The analysis of defined molecular markers in the primary tumor, improved imaging techniques and particularly sentinel lymph node biopsy could facilitate the identification of patient groups who can undergo limited surgery without additional risk.

\begin{tabular}{ll}
\hline KARGER & @ 2005 S. Karger GmbH, Freiburg \\
Fax +497614520714 & Accessible online at: \\
$\begin{array}{l}\text { E-mail Information@Karger.de } \\
\text { www.karger.com }\end{array}$ & www.karger.com/onk
\end{tabular}

Prof. Dr. med. Dr. h.c. P. M. Schlag

Charité - Universitätsmedizin Berlin, Campus Berlin-Buch

Klinik für Chirurgie und Chirurgische Onkologie

Lindenberger Weg 80, 13125 Berlin, Germany

Tel. +49 3094171 40-0, Fax -4

E-mail schlag@rrk.charite-buch.de 


\section{References}

1 Tani M, Takeshita K, Inoue H, Iwai T: Adequate endoscopic mucosal resection for early gastric cancer obtained from the dissecting microscopic features of the resected specimens. Gastric Cancer 2001;4:122-131.

2 Kinami S, Miwa K, Ishii K, Miyashita T, Fushida S, Fujimura T, Ohta T: Limited surgery for early gastric cancer using lymphatic basin dissection - a sure method of sentinel node biopsy for gastric cancer. Gan To Kagaku Ryoho 2005;32:405-410.

3 Naka T, Ishikura T, Shibata S, Yamaguchi Y, Ishiguro M, Yurugi E, Nishidoi H, Kudoh H, Murakami S, Tsujitani S: Laparoscopy-assisted and open distal gastrectomies for early gastric cancer at a general hospital in Japan. Hepatogastroenterology 2005;52: 293-297.

4 Skoropad V, Berdov B, Zagrebin V: Clinicopathological features and outcome of surgical treatment of 149 patients with early (pT1) gastric cancer. Onkologie 2005;28:247-252.

5 Abe S, Yoshimura H, Tabara H, Tachibana M, Monden N, Nakamura T, Nagaoka S: Curative resection of gastric cancer: limitation of peritoneal lavage cytology in predicting the outcome. J Surg Oncol 1995;59:226-229.

6 Gretschel S, Bembenek A, Ulmer C, Hunerbein M, Markwardt J, Schneider U, Schlag PM: Lymphatic mapping and sentinel lymph node biopsy in gastric cancer. Chirurg 2003;74:132-138.

7 Isozaki H, Kimura T, Tanaka N, Satoh K, Matsumoto S, Ninomiya M, Ohsaki T, Mori M: An assessment of the feasibility of sentinel lymph node-guided surgery for gastric cancer. Gastric Cancer 2004; 7:149-153.

8 Karube T, Ochiai T, Shimada H, Nikaidou T, Hayashi H: Detection of sentinel lymph nodes in gastric cancers based on immunohistochemical analysis of micrometastases. J Surg Oncol 2004;87: 32-38.

9 Song X, Wang L, Chen W, Pan T, Zhu H, Xu J, Jin M, Finley RK, III, Wu J: Lymphatic mapping and sentinel node biopsy in gastric cancer. Am J Surg 2004;187:270-273

10 Gretschel S, Bembenek A, Ulmer C, Hünerbein M, Markwardt J, Schneider U, Schlag PM: Prediction of gastric cancer lymph node status by sentinel lymph node biopsy and the Maruyama computer model. Eur J Surg Oncol 2005: in press.

11 Cai J, Ikeguchi M, Tsujitani S, Maeta M, Kaibara N: Micrometastasis in lymph nodes of mucosal gastric cancer. Gastric Cancer 2000;3:91-96.

12 Yasuda K, Adachi Y, Shiraishi N, Inomata M, Takeuchi H, Kitano S: Prognostic effect of lymph node micrometastasis in patients with histologically node-negative gastric cancer. Ann Surg Oncol 2002;9:771-774.

13 Simsa J, Hoch J, Leffler J, Schwarz J, Pospisil R, Vajtrova R: Sentinel node biopsy in gastric cancer: preliminary results. Acta Chir Belg 2003;103: 270-273.

14 Ajisaka H, Miwa K: Micrometastases in sentinel nodes of gastric cancer. Br J Cancer 2003;89:676680 .

15 Osaka H, Yashiro M, Sawada T, Katsuragi K, Hirakawa K: Is a lymph node detected by the dyeguided method a true sentinel node in gastric cancer? Clin Cancer Res 2004;10:6912-6918. 